\title{
A Influência do Eixo Visuo-Podal na Regulaçáo do Equilíbrio Morfoestático em Idosos
}

\author{
The Influence of Vision-Foot Axis In Morphoestatic Balance Regulation In Elderly
}

\author{
Nélio Silva Souza', Ana Carolina Gomes Martins ${ }^{1}$, Dionis de Castro \\ Dutra Machado ${ }^{2}$,Kátia Pedreira Dias', Sergio Nader ${ }^{4}$,Victor Hugo Bastos ${ }^{5}$
}

\section{RESUMO}

Introduçáo. A boa postura é o estado de equilíbrio musculoesquelético que protege as estruturas de sustentaçáo do corpo, podendo diminuir a possibilidade de quedas e suas consequências. Queda é o deslocamento náo intencional do corpo com incapacidade de correçáo em tempo hábil, sua etiologia é bastante complexa e o sistema sensorial proprioceptivo tem apresentado fortes evidências como fator causal. Embora essas correlações tenham sido negligenciadas pela maioria dos profissionais de saúde, a correçáo do sistema sensorial proprioceptivo, através de seus principais elementos: visual (convergência) e podal (valgo/varo), parece fundamental para a obtenção do equilíbrio postural. Objetivo. Discutir a influência visual e podal no equilíbrio morfoestático em idosos, bem como a prevenção de eventuais quedas. Método. Foi realizada uma busca nas bases de dados: Index Medicus; Biological Abstracts; Pub Med; Bireme; PEDro e Lilacs e selecionados os artigos pertinentes ao tema. Discussáo. A Posturologia Clínica visa resgatar o controle postural com estímulos mantidos em tempo hábil para promover mudanças no sistema sensorial e esquema corporal (neuroplasticidade), prevenindo quedas pela funcionalização do alinhamento e da estabilidade. Conclusáo. As quedas ocorrem independente da idade e a regulaçáo do eixo visuo-podal parece resgatar o equilíbrio postural e prevenir as quedas em idosos.

Unitermos. Controle Postural, Queda, Olhos, Pés, Equilíbrio, Idoso.

Citação. Souza NS, Martins ACG, Machado DCD, Dias KP, Nader S, Bastos VH. A Influência do Eixo Visuo-Podal na Regulação do Equilíbrio Morfoestático em Idosos.

\begin{abstract}
Introduction. Good posture is the state of muscle-skeletal balance that protects the body supporting structures may decrease the likelihood of falls by reduces of the possibility falls and their consequences. Fall is the unintentional movement of the body with inability to stand still timely, its etiology is complex and proprioception sensory system has shown strong evidence as a causal factor. Although these correlations have been neglected by most health professionals, the correction of the proprioception sensory system, through its main elements: the eyes (convergence) and feet (varus/valgus), seems essential to obtain postural balance. Objective. Discuss the influence of the eyes and feet morphoestatic balance in the elderly, as well as preventing some falls. Method. A literature search was carried out by basis of bases: Index Medicus; Biological Abstracts; Pub Med; Bireme; PEDro e Lilacs, and paper were relating theme select. Discussion. Hence the Clinical Posturology proposes to recover postural control stimuli maintained timely to promote changes in sensory system and body scheme (neuroplasticity) preventing falls by improving the alignment and stability. Conclusion. The falls occur regardless of age Falls happen is age independent and vision-foot axis appearance ransom of the postural balance and prevent falls in elderly.
\end{abstract}

Keywords. Postural Control, Fall, Eyes, Foots, Balance, Aged.

Citation. Souza NS, Martins ACG, Machado DCD, Dias KP, Nader $\mathrm{S}$, Bastos VH. The Influence of Vision-Foot Axis In Morphoestatic Balance Regulation In Elderly.
Trabalho realizado na Universidade Federal Fluminense, UFF, Niterói-RJ, Brasil.

1. Fisioterapeuta, UNFESO, Mestrando em Ciências da Reabilitação, UNISUAM, Rio de Janeiro-RJ, Brasil.

2. Fisioterapeuta, Mestre, Professora assistente do departamento do departamento de fisioterapia da Universidade Federal do Piauí, UFPI/CMRV, Teresina-PI, Brasil.

3. Formação, Mestre, Professora do serviço de Geriatria, UFF, Niterói-RJ, Brasil.

4. Médico, Biólogo, Professor Assistente UNESA, Rio de Janeiro-RJ, Brasil.

5. Fisioterapeuta, Professor Adjunto do departamento do departamento de fisioterapia da Universidade Federal do Piauí, UFPI/CMRV, Teresina-PI, Brasil.
Endereço para correspondência: Nélio Silva de Souza Rua Papa Pio XII no 170 - Jardim Cascata CEP 25964-330, Teresópolis-RJ, Brasil. Tel.: (21) 2642-5895 / 9504-1558 E-mail: neliosds@bol.com.br 


\section{INTRODUÇÃO}

A boa postura é o estado de equilíbrio músculoesquelético que protege as estruturas de sustentação do corpo $^{1}$, prevenindo eventuais quedas ${ }^{2}$. A adoção da postura bípede constitui um desafio para os seres humanos, uma vez que envolve questóes como equilíbrio, controle motor e adaptaçóes inerentes ao estado de constante movimento $^{3}$. Segundo o consenso desenvolvido pela Associação Médica Brasileira e o Conselho Federal de Medicina, queda é o deslocamento não intencional do corpo para um nível inferior à posição inicial com incapacidade de correção em tempo hábil, determinado por circunstâncias multifatoriais, comprometendo a estabilidade postural do indivíduo. Nos Estados Unidos da América (EUA) as quedas são eventos que frequentemente causam lesóes, constituindo a principal causa de morte acidental em pessoas com idade acima de 65 anos. A incidência mundial de quedas em idosos apresenta uma frequência variável de um país para o outro ${ }^{4-6}$ e no Brasil, é de aproximadamente $40 \%{ }^{4}$. As pessoas caem independente da idade, a queda é um evento comum experimentado por todos durante os diversos estágios da vida. Quando esta ocorre em crianças e adultos jovens são facilmente esquecidas e não apresentam importantes consequências na maioria dos casos. Em contrapartida, as quedas em idosos constituem uma importante causa de morbidade e mortalidade, sendo responsável por prolongado tempo de tratamento e de grandes gastos em saúde ${ }^{7}$. Nesse contexto, os idosos podem ser classificados em dois grupos: (1) os que não caem (menos que dois eventos por ano) e (2) os que caem (mais que dois eventos por ano) ${ }^{2}$.

O evento da queda (EQ) constitui um problema de saúde pública que pode acelerar o processo de dependência ${ }^{8}$. Sua etiologia é bastante complexa, pois sua causa pode ser de natureza extrínseca (relacionada com o ambiente) ou intrínseca (relacionada com o indivíduo). As primeiras constituem fatores óbvios e são facilmente detectados, como chão escorregadio e áreas pouco iluminadas. Dentre os segundos fatores, que incluem alteraçóes fisiológicas relacionadas ao envelhecimento, doenças e medicamentos ${ }^{9}$, as alteraçôes sensoriais proprioceptivas podem ser os grandes fatores causadores ${ }^{10,11}$ e geralmente são negligenciados pela maioria dos profissionais de saúde.
O sistema tradicionalmente relacionado com o equilíbrio postural é o sistema sensorial, que é composto pelos sistemas: visual; vestibular e proprioceptivo ${ }^{2,7}$. Parece que existe uma ordem hierárquica entre eles a fim de fornecer o ajuste postural estático, sendo os pés e os olhos os captores principais desse sistema. Assim, o controle do Sistema Tônico Postural (STP) tem sido considerado multimodal, pois possui mais de uma entrada aferente sensorial ${ }^{10-13}$. Somente $10 \%$ da população parece responder aos critérios de normalidade postural e ajuste sensorial ideal, o que pode proporcionar maior controle postural. Os outros $90 \%$, incluindo idosos, apresentam alterações em pelo menos um desses captores ${ }^{11}$.

A aquisição da postura corporal adequada necessita de um sistema muscular e proprioceptivo equilibrado com ausência de forças contrárias anormais, controladas pela interação dos diferentes níveis cerebrais (medular, mesencefálico e cortical $)^{10,11}$. Estudos têm revelado que alteraçóes nos captores podal e ocular parecem ser a causa dos desequilíbrios posturais e suas correçóes parecem ser fundamentais para a obtenção desse equilíbrio e consequente prevenção do EQ em idosos ${ }^{10-12,14-15}$. Considerando o exposto, o objetivo desse trabalho é discutir a influência visual e podal no equilíbrio morfoestático em idosos, bem como a prevenção do EQ.

\section{MÉTODO}

Esta revisão da literatura utilizou livros das áreas de Posturologia Clínica e Geriatria, tanto pátrio como não pátrio (Inglês e Francês), dos períodos de 1997 a 2010. Os livros referenciados são clássicos e de fundamental importância para a explanação do tema apresentado. Além disso, foram selecionados artigos indexados nas seguintes bases de dados: Index Medicus; Biological Abstracts; Pub Med; Bireme; PEDro e Lilacs, utilizando-se as palavraschave: controle postural; queda; olhos; pés; equilíbrio e idoso, bem como suas similares em Inglês e Francês. Os artigos compreenderam o período de busca de 1973 a 2011, sendo o maior volume de informaçóes oriundo dos últimos 10 anos, devido à escassez de material bibliográfico com tal abordagem. Assim, foram utilizadas 37 referências correspondentes aos últimos dez anos e as demais (19 referências) com mais de dez anos de publicação. 


\section{REVISÃO DA LITERATURA}

Sistemas sensoriais de controle postural estático

Os sistemas relacionados com o controle do equilíbrio tônico postural são: visual; vestibular e proprioceptivo, que pode ser subdividido em endocepção e exterocepçáo $0^{2,7,16-19}$. As informaçôes vestibulares na condição estática, parecem estar sob a dependência da informação visual, pois os núcleos vestibulares não são apenas reservados ao ouvido interno, mas são verdadeiros centros de integração do STP. Isso foi demonstrado em estudos feitos em gato, o qual foi imobilizado diante de um fundo com um quadro de linhas geometricamente visíveis. Para registro das informaçóes dos núcleos vestibulares, foram utilizados minieletrodos os quais não registraram qualquer atividade na posição estática. Entretanto, se o fundo geométrico fosse movimentado sua atividade poderia ser registrada, demonstrando que suas integraçóes e ajustes estão na dependência da informação visual ${ }^{18,20,21}$. Portanto, os estímulos sensoriais prioritários no ajuste do controle postural estático parecem ser basicamente visual e podal, sendo o vestíbulo considerado um identificador de deslocamentos rápidos (aceleração e desaceleração - angular e linear) ${ }^{10,11,20}$.

O STP é composto por um tripé, em que as hastes são: (1) os captores; (2) o centro de processamento central e (3) os efetores. Os captores são os receptores sensitivos localizados nos órgãos sensoriais (principalmente, os olhos e os pés), que associam endo e exterocepção. O centro de processamento central é composto por diversas áreas cerebrais (formação reticular, colículos, núcleos da base, cerebelo, tálamo, corpo caloso, comissuras, diencéfalo e córtex sensorial e motor), que regulam a tonicidade das fibras tipo I (estabilizadoras) dos músculos anti-gravitacionais, que são os efetores deste sistema ${ }^{10,11,19,22}$.

Quando se trata da posição ortostática, os pés são os primeiros a enviar informações sensoriais proprioceptivas que partem de diversas regiōes como as articulaçôes, os músculos e a pele (exterocepção) ${ }^{11,23}$. Estudos em plataforma de pressão revelaram que as informaçóes exteroceptivas parecem ser mais importantes que as demais, para fins de regulação do STP 11,16,24. Dos exteroceptores, os receptores de Ruffini, Paccini e Merkel estão envolvidos nas informaçóes primárias durante o suporte de peso corporal (pressão) no equilíbrio postural estáti- $\mathrm{co}^{7,25-29}$. Estes enviam informações aferentes ao centro de processamento central pelas vias lemiscal e extra-lemiscal, que integram reflexos de feedback e feedforward, essenciais para a manutenção da postura ortostática ${ }^{11,23,30-33}$. Alteraçôes das informações sensoriais podem levar a desajustes biomecânicos neste captor, como os pés valgo e/ou varos (simétricos ou assimétricos), bem como os pés compensadores e de duplo componente (analisado em apoio unipodal) ${ }^{11,34-37}$.

O sistema visual, assim como o podal, é um captor interno e externo, responsável por prover informações extero e endoceptivas ${ }^{11,19,30,38,39}$. A primeira refere-se à propriocepçáo sensorial vinda da retina e suas alteraçóes estão relacionadas com os distúrbios de refração (miopia, astigmatismo e hipermetropia), enquanto a segunda relaciona-se com a informação proprioceptiva motora da musculatura extra-ocular e suas alteraçóes estão relacionadas com os distúrbios de convergência e heteroforia, que são as mais importantes para os posturólogos ${ }^{8,10,11,40}$. As informações proprioceptivas vindas dos músculos extraoculares chegam ao centro de processamento central pelos respectivos nervos cranianos: troclear (músculo oblíquo superior); abducente (músculo reto lateral); oculomotor (músculo obliquo inferior e retos medial, superior e inferior). Estas informaçôes são integradas nos núcleos desses nervos cranianos (tronco cerebral) com o núcleo do nervo acessório (músculos esternocleidomastóideo e trapézio), que por sua vez faz sinapse com motoneurônios alfa da medula cervical (C1 a C4), constituindo a via oculocefalogíria, que submete os músculos da cabeça, pescoço e ombros aos dos olhos e vice-versa. Esta via foi descrita inicialmente por Meyer \& Baron em 1973 8 ,11,18,41-43.

\section{Alteraçôes sensoriais dos sistemas de controle postural estático em idosos}

O envelhecimento é um processo dinâmico, marcado por alterações neurofisiológicas, expressas através de alterações morfofuncionais e bioquímicas nos diversos sistemas ${ }^{44}$. Referente ao sistema musculoesquelético do idoso ocorre restrição capsular com diminuição do movimento artro e osteocinemático, comprometendo a amplitude de movimento total. No nível muscular, ocorre redução de sua massa (área de secção transversa), principalmente devido à perda das fibras do tipo II (força), 
enquanto as fibras do tipo I (estabilidade) se mantêm ou podem até mesmo aumentar sua quantidade ${ }^{7}$.

O sistema visual é essencial para situar o idoso no espaço e nele ocorrem dois tipos de alteraçóes, uma relacionada à acuidade visual e outra relacionada à musculatura extra-ocular. As primeiras são alteraçôes bem conhecidas como: desordens de refração; glaucoma; cataratas; degeneração macular e presbiopia. Entretanto, pouco se sabe sobre as alteraçóes do sistema oculomotor do idoso, que parece sofrer perdas progressivas, com declínio dos movimentos oculares lentos, movimento sacádicos, nistágmo optocinético e a convergência ocular ${ }^{7}$. Parece que essas alteraçóes musculares podem ocorrer da mesma forma que ocorre no corpo humano, uma vez que são músculos do mesmo tipo morfológico (estriados esquelético $)^{45}$. Na pele ocorre redução do número de exterorreceptores e os remanescentes diminuem sua sensibilidade, proporcionando ao idoso menor percepção de tato, temperatura e vibração (pressão), que é essencial para o controle postural e bipedia ${ }^{15}$.

\section{Correção dos principais captores posturais}

A reorganização tônica dos músculos extra-oculares é possível ${ }^{11}$, uma vez que estes são músculos estriados esqueléticos, estão sujeitos as mesmas mudanças morfológicas que os demais músculos do corpo humano ${ }^{45}$. Portanto, no tratamento das deficiências de convergência são utilizados exercícios de auto re-educação para correçâo tônica desses músculos ${ }^{11}$. Os exercícios consistem em retreinar os três tipos de convergência (tônica, acomodativa e fusional), por meio da fixação de um objeto pontiagudo (caneta) ao nível dos olhos, aproximando na direção da raiz do nariz. Isto faz com que o reto lateral do olho hipoconvergente seja inibido (inibição recíproca - Princípio de Sherrington) e o reto medial seja fortalecido ${ }^{11,46}$. A magneto terapia, juntamente com os exercícios, também tem sido utilizada na correção deste captor. Seu objetivo é relaxar a musculatura extra-ocular ao aplicar o pólo positivo (miorelaxante) na área paraorbital, que atua diretamente sobre o reto lateral e reflexamente sobre o obliquo inferior do lado hipoconvergente dos olhos, promovendo o estiramento da fibra intra-fusal (inibição autógena) ${ }^{47}$.

O uso das palmilhas proprioceptivas foi inicialmente relatado em 1980, pelo médico francês René
Bourdiol. Seu princípio está fundamentado na ação de peças colocadas sob a pele e músculos plantares, tendo como objetivo a reorganização tônica e exteroceptiva das cadeias musculares, influenciando na postura corporal por meio de reflexos de correção monossinápticos (feedback) e polissinápticos (feedforward). Estas palmilhas são exteroceptivas, pois estimulam os exteroceptores plantares de adaptação lenta e rápida (tipo I e II, respectivamente) $11,13,29,33,48$.

As informaçóes vindas dos exteroceptores plantares, bem como as informações sensoriais endoceptivas vindas do sistema visual, interagem com o cerebelo para que ocorra influência do mesmo sobre a atividade tônica muscular anti-gravitacional, concretizando sua relevância no controle da postura e do movimento humano ${ }^{49}$. Este tem sido denominado eixo visuo-podal e suas informaçóes podem conflitar nas áreas de processamento cerebelar (vérmix $)^{10}$. Portanto, na maioria dos casos devem ser corrigidos concomitantemente.

\section{DISCUSSÃO}

O presente estudo objetivou discutir a influência visual e podal no equilíbrio morfoestático em idosos, bem como a prevençáo de eventuais quedas. Neste sentido, considera-se que algumas perdas no Sistema Nervoso Central (SNC) envelhecido já são bem conhecidas como a diminuição de liberação de neurotransmissores, velocidade de condução dos neurônios sensoriais (retardo de 20 a $30 \mathrm{~ms}$ ) e motores dos SNC e periférico ${ }^{7,50}$. Estudos, até o momento, têm enfocado somente o hipocampo, o bulbo olfatório e o córtex cerebral, que apresenta menor perda no número de neurônios que o tronco encefáli$\mathrm{co}^{7,51}$. Entretanto, pouco se sabe sobre as áreas que participam do controle do equilíbrio tônico postural (cerebelo, tronco cerebral e medula espinhal) ${ }^{51}$. Parece que essas alteraçôes fisiológicas (senescência) podem prejudicar a função dos centros reguladores da postura anti-gravitacional, favorecendo atraso na regulação do STP e consequentes falhas no ajuste postural compensatório (feedback) e antecipatório (feedforward), favorecendo o EQ e suas consequências ${ }^{52}$.

Novas sinapses (sinaptogênese) formam-se no cérebro de adultos e esse brotamento neuronal também foi demonstrado no cérebro de animais com envelhecimen- 
to, porém o seu grau e magnitude parece declinar. Assim, admiti-se que este evento possa ocorrer no cérebro humano envelhecido ${ }^{7}$. Habitualmente, a maioria das células do SNC tende a diminuir. Contudo, curiosamente, a neuroglia (célula da glia essencial para a neuroplasticidade) parece aumentar em alguns núcleos de indivíduos com idade entre 26 e 82 anos $^{2}$. Estudos têm demonstrado melhora no equilíbrio postural em idosos brasileiros, que poderia estar relacionado com os mecanismos de neuroplasticidade, feedback e feedforward, que parecem reorganizar o registro de mudanças do controle postural, integrando um novo esquema corporal, fornecendo maior estabilidade postural, maior capacidade de recuperação do equilíbrio e consequentemente prevenção do $\mathrm{EQ}^{16,52}$.

A real relação dos olhos com a postura corporal tem sido evidenciada ao exercer vibraçóes em pequenas amplitudes $(0,1)$ e frequência variada $(10 \mathrm{a} 80 \mathrm{~Hz})$ na área paraorbital correspondente a região da musculatura extra-ocular. Os efeitos posturais foram demonstrados com os indivíduos com os olhos fechados e os deslocamentos corporais demonstraram ser dependentes da estimulação dos respectivos músculos: retos inferiores (retro-pulsão do corpo); retos superiores (antero-pulsão do corpo) e reto lateral de um lado e medial do outro (deslocamento latero-lateral do corpo). Neste mesmo estudo, foi evidenciado o efeito cinestésico proprioceptivo da musculatura extra-ocular sobre o arranjo postural. Em um indivíduo com os olhos fechados e tronco bloqueado, a vibração do músculo reto lateral de um lado induziu a sensação ilusória de rotação do tronco para o lado oposto, independente do lado estimulado. $\mathrm{O}$ mesmo foi demonstrado quando a cabeça foi fixada e o tronco se manteve livre, demonstrando que tanto a cabeça quanto o tronco tendem a deslocar para o lado contralateral a estimulação ${ }^{53}$. Diversos estudos em idosos têm demonstrado a importância da correção deste captor a fim de reorganizar o equilíbrio postural ${ }^{10}$.

No sistema visual ocorrem dois tipos de alteração patológicas (senelidade), uma relacionada à acuidade visual dos bastonetes da visão (exterocepçáo) e outra relacionada à motricidade extra-ocular (endocepção) ${ }^{8,11,40}$. As alteraçôes mais conhecidas são Glaucoma, cataratas, degeneração macular e presbiopia (exterocepção). Contudo, pouco se sabe sobre o sistema oculomotor do ido- so, que parece sofrer perdas progressivas, como o declínio dos movimentos oculares lentos, movimento sacádicos, nistágmo optocinético e a convergência ocular (endocepção $)^{7}$, mas não se sabe ao certo como e porque isso ocorre, ou mesmo se o indivíduo já apresentava esta deficiência antes de envelhecer.

Evidências demonstraram que as respostas posturais resultantes da estimulação exteroceptiva plantar estão sempre na mesma direção e sentido, independente dos indivíduos testados e parece que essas zonas plantares possuem um mecanismo reflexo característico e padronizado. $\mathrm{O}$ estudo em questão utilizou estimulaçôes vibratórias $(80 \mathrm{~Hz})$ em plataforma de estabilometria, sendo divididos em dois grupos: estimulações assimétricas e simétricas. No primeiro, foi observado que o deslocamento corporal seguia oposto e oblíquo em relação à zona de estimulação plantar, independente do lado estimulado. Já o segundo grupo, demonstrou que as zonas plantares (calcâneo, antepé e bordas podais) ao serem estimuladas bilateralmente, promovem um deslocamento retilíneo e oposto a zona de estimulaçãa ${ }^{54}$. Estudos em idosos têm demonstrado que, ao analisar a reação compensatória (feedback) nas quedas com apoio bipodal e unipodal, tanto em superfície firme quanto instável, pode-se observar a importância da informação exteroceptiva antes e depois do bloqueio anestésico dos nervos cutâneo-plantares (medial e lateral). O bloqueio exteroceptivo permitiu evidenciar o controle postural na sua ausência, confirmando seu importante papel na regulação do equilíbrio postural em idosos ${ }^{14}$.

Durante o processo de senescência (envelhecimento fisiológico) os corpúsculos dos exteroceptores plantares se tornam mais esparsos, com distribuição irregular e muito variáveis em tamanho e forma. Estas alteraçóes cutâneas envolvem os receptores de Meissner (detecta o toque leve) e Paccini (tato, sensibilidade vibratória e pressão), que sofrem alteraçôes morfológicas e diminuição de sua densidade ao longo dos anos. Entretanto, os corpúsculos de Merkel, que são receptores de adaptação lenta e que codificam a sensibilidade a pressão, parecem não demonstrar alterações significativas relacionadas à idade ${ }^{7}$. Portanto, a exterocepção para a postura bípede parece ser um ponto fundamental e pode ser estimulada, mesmo em idosos, com a finalidade de equilibrar o STP e diminuir 
a possibilidade de quedas durante as atividades diárias.

As correçóes dos captores posturais podem ser realizadas por meio de exercícios de auto-reeducação ocular (convergência), magneto terapia ${ }^{10,11,47}$ e colocação de palmilhas proprioceptivas (equilíbrio ântero-posterior e do valgo/varo dos pés $)^{15,48}$, capazes de resgatar a simetria sensorial direita-esquerda dos captores, melhorando a estabilidade postural, prevenindo o EQ e suas consequências $^{10,11}$. Estas correçóes devem permanecer no mínimo 10 meses a 1 ano, dependendo do indivíduo ${ }^{11}$. O estímulo mantido é o ideal para liberar ácido gama-amino-butírico (GABA), inibindo o neurônio pós-sináptico e estimulando a neuroglia, que ativa o segundo mensageiro ligado as quinases e promove a transcrição de genes imediatos, intermediários e tardios ${ }^{55}$, conduzindo a modificação na morfofuncionalidade dos neurônios das áreas do STP, aumentando suas conexôes e modificando o esquema corporal de base do indivíduo ${ }^{16,52}$.

Evidências demonstram que na ausência de doenças crônicas, clinicamente diagnosticadas, os estímulos visuais (motricidade extra-ocular) e vibratórios (exteroceptivos) estão geralmente diminuídos em idosos, podendo perturbar o ajuste do sistema sensorial ${ }^{2,7}$ e seu equilíbrio tônico postural ${ }^{11}$, que está intimamente relacionado às quedas ${ }^{2}$. Entretanto, não se sabe até o momento, a real causa de descompensação do STP, pois este tem demonstrado alteraçóes tanto em crianças ${ }^{56}$, adultos jovens ${ }^{11}$ e idosos ${ }^{10,14,15}$, independente da idade. Parece que as perdas fisiológicas relacionadas à senescência podem ser somente fatores intensificadores de uma descompensação pré-existente no STP, que fica muito mais evidente no idoso, devido às consequências mais graves que nos adultos, jovens e crianças.

\section{CONCLUSÃO}

Neste contexto, pode-se concluir que, o EQ parece ocorrer por toda a vida independente da idade, sua incidência (40\%) pode ser questionável, pois boa parte das pessoas não relata este evento, que pode ser erroneamente atribuído a idade. A prevenção do EQ em idosos tem sido grande foco da pesquisa mundial e a Posturologia Clínica parece resgatar o controle postural com estímulos mantidos em tempo hábil para promover mudanças no sistema sensorial e nas áreas do esquema corporal (neu- roplasticidade) e consequentemente prevenir o EQ e suas consequências.

Parece relevante destacar que o presente conceito é base mecânica e neurofisiológica para diversos métodos e propostas terapêuticas que vem ao longo dos últimos anos buscando consolidação científica e terapêutica, como Tai Chi Chuan e algumas recentes como Dança Sênior, Pilates e Reeducação Postural Global. Nesta vertente, a correção dos captores posturais deve ser realizada em conjunto com as demais terapêuticas, com o intuito de resgatar a funcionalidade do indivíduo como um todo, pois o movimento intencional é acompanhado e seguido de fenômenos posturais. Assim, o foco do presente estudo foi colocar em pauta uma abordagem terapêutica pouco explorada, com fortes evidências e que deve compor o arsenal terapêutico dos profissionais de saúde, uma vez que a tendência será a reabilitação neuro-ortopédica, com base nos estudos de neurociências. Em contrapartida, nota-se que mais estudos devem ser realizados e de forma específica em grupos de idosos para estreitar mais as relações dos captores posturais e o envelhecimento.

\section{REFERÊNCIAS}

1.O'sullivan PB, Michell T, Bulich P, Waller R, Holte J. The relationship between posture and back muscle endurance in industrial workers with flexionrelated low back pain. Man Ther 2006;11:264-71.

http://dx.doi.org/10.1016/j.math.2005.04.004

2.Freitas EV, Lígia PY, Cançado FAX, Doll J, Gorzoni ML. Tratado de Geriatria e Gerontologia. 2o ed. Rio de Janeiro: Guanabara Koogan; 2006, p.950-60. 3.Villeneuve PH. Régulation du tônus postural par informations podales (endereço na internet). Association Posturologie Internationale: Pierre Gagey. (atualizado em: 01/2012; acesso em: 03/2009). Disponível em: http://www. posturologie.asso.fr/articles/villeneuve.html

4.Álvares LM, Lima RC, Silva RA. Ocorrência de quedas em idosos residentes em instituiçôes de longa permanência em Pelotas, Rio Grande do Sul, Brasil. Cad Saúde Pública 2010;26:31-40.

http://dx.doi.org/10.1590/S0102-311X2010000100004

5.Avidan, AY, Fries BE, James ML, Szafara KL, Wright GT, Chervin RD. Insomnia and hypnotic use, recorded in the minimum data set, as predictors of falls and hip fractures in Michigan nursing homes. J Am Geriatr Soc 2005;53:955-62.

http://dx.doi.org/10.1111/j.1532-5415.2005.53304.x

6.Marchetti GF, Whitney SL. Older Adults and Balance Dysfunction. Neurol Clin 2005;23:785-805.

http://dx.doi.org/10.1016/j.ncl.2005.01.009

7.Guccione A. Geriatric Physical therapy. $2^{\circ}$ ed. United States of American: Mosby; 2000, 459p. 
8. Weber B, Villeneuve P. Posturologie clinique: dysfonctiones motrices et cognitives. Masson 2007;129-38p.

9.American geriatrics society. Guideline for the prevention of falls in older persons. JAGS 2001;49:664-72.

http://dx.doi.org/10.1046/j.1532-5415.2001.49115.x

10.Gagey PM, Weber B. Posturologia: Regulaçẫo e distúrbios da posição ortostática. São Paulo: Manole; 2000, 150p.

11.Bricot B. Posturologia Clínica. São Paulo: Cies Brasil; 2010, 249p.

12.Cyrulik BS. Causes biomécaniques des troubles musculo-squelettiques (TMS): méthode ora pour le diagnostic relatif de l'appareil locomoteur, prévention et thérapie. Rev Thecquin 2010; 510:31-8.

13.Carpenter MG, Murnaghan CD, Inglis JT. Shifting the balance: evidence of an exploratory role for postural sway. Cogn, Behav and Syst Neurosc 2010;171:196-204.

14.Bussel MC, Breniere Y. Influence of plantar cutaneous afferentes on early compensatory reactions to forward fall. Brain Res. 1990;39:319-24.

15.Palluel E. Effets du port de semelles à picots sur le contrôle postural quasistatique et la sensibilité cutanée de la personne âgée (Tese). Marseille: Universite Joseph Fourier, 2008, 204p.

16.Scoppa F. Posturologia: dalla dinamica non lineare alla transdisciplinarietà. Agressologie, 2003;15:28-47.

17.Fitzpatrick R, Mccloskey DI. Proprioceptive, visual and vestibular thresholds for the perception of sway during standing in humans. J Physiol Lond 1993;478:173-6.

18.Baron JB, Bessineton JC, Bizzo G, Noto R, Tévanian G, Pacifici M. Corrélations entre le lonctionnement dês systems sensori-moteur labyrintique et oculomoteur ajustant, les déplacements du centre de gravité du corps de l'homme en orthostatisme. Agressologie 1973;14:79-86.

19.Gagey PM, Baron JB, Ushio N. Introduction to clinical posturology. Agressologie 1980;21:119-23.

20.Xerri C, Barthelemy J, Harlay F, Borel L, Lacour M. Neuronal coding of linear motion in the vestibular nucleio of the alert cat. I. Response characteristics to vertical otolith stimulation. Exp Brain Res 1987;65:569-81.

21.Xerri C, Barthelemy J, Borel L, Lacour M. Neuronal coding of limotion in the vestibular nuclei of the alert cat. III. Dynamic characteristic. VisualOtolith interactions. Exp Brain Res 1988;70:299-309.

22.Zaehle T, Herrmann C. Neural synchrony and white matter variations in the human brain - between evoked gamma frequency and corpus callosum morphology. Relation Elselvier2011;79:49-54.

23. Camargo MR, Fregonesi CEPT. A importância das informaçốes aferentes podais para o controle postural. Rev Neurocienc 2011;19:165-70.

24.Pietro G, Morasso, Schieppati M. Can Muscle Stiffness Alone Stabilize Upright Standing? The American Physiological Society. J of Neurophysiology 1999;82:1622-6.

25.Perry SD, Mciroy WE, Maki BE. The role of plantar cutaneous mechanoreceptors in the control of compensatory stepping reactions evoked by unpredictable, multi-directional perturbation. Elsevier Science 2000;887:401-6. 26.Borg FG. An inverted pendulum with a springy control as a model of human standing. Biological Physics. 2005;1:1-22.

27. Halata Z. Ruffini corpuscle - a stretch receptor in the connective tissue of the skin and locomotion apparatus. Progress in brain research 1988;74:221-9. http://dx.doi.org/10.1016/S0079-6123(08)63017-4

28.Diener HC, Horak FB, Nashner LM. Influence of stimulus parameters on human postural responses. Journal of neurophysiology 1988;59:6.

29.Kennedy PM, Inglis JT. Distribution and behavior of glabrous cutaneous receptors in the human foot sole. J Physiol 2002;538:995-1002.

http://dx.doi.org/10.1113/jphysiol.2001.013087

30.Kavounoudias A, Roll J, Anton JL, Nazarian B, Roth M, Roll R. Proprio- tactile integration for kinesthetic perception: An fmri study. Neurophysicologia 2008;46:567-75.

http://dx.doi.org/10.1016/j.neuropsychologia.2007.10.002

31.Deliagina TG, Orlovsky GN, Zelenin PV, Beloozerova IN. Neural Bases of Postural Control. Physiology 2006;21:216-25.

http://dx.doi.org/10.1152/physiol.00001.2006

32.Layne CS. Interactions between automatic postural adjustments and anticipatory postural patterns accompanying voluntary movement. J neurosc 1991;61:241-54.

33. Finley JM, Dhadher YY, Perreault EJ. Regulation of Feed-forward and Feedback Strategies at the Human Ankle during Balance Control. Conf. Proc. IEEE Emg. Med Biol Soc, 2010;10:7265-8.

34.Dominici, Chanbon, Meunier-Guttin-Cluze, Mouysset, Bricot. Une asymétrie morphostatique peut-elle provoquer ou induire des douleurs du système locomoteur? Résonances Européennes du Rachis 2005;13:1701-4.

35.Gallozzi C. Il ruolo dell'equilibrio corpóreo nella traumatologia dello sport. Medicina dello sport 2003;53(4):17.

36.Cunha HM. The postural deficiency syndrome (PDS). Agressologie 1987;28:941-3.

37. Bricot B. Postura normal y posturas patológicas. La reviste del instituto de posturologia y podoposturologia 2008;1:1-13.

38. Mallong SP. Suivi longitudinal par étude prospective de patients douloureux au cours d'une Reprogrammation Posturale Globale (RPG). Résonances Européennes du Rachis 2005;14:1753-6.

39.Kavounoudias A, Gilhodes JC, Roll R, Roll JP. From balance regulation to body orientation: two goals for muscle proprioceptive information processing? Springer-Verlag 1999;124:80-8.

40.Weber B, Villeneuve P. Posturologie clinique: tonus, posture et attitudes. Masson; 2010, 203p.

41.Baritz M, Cristea L, Cotoros D, Stanciu A. Retinal image and oculo-motor equilibrium analyze using recordings of human body stability-posture. Recent advances in signal processing, robotics and automation 2010;258-63.

42.Bilello G, Caradonna D, Caradonna C, Cuccia AM, Manzella A. Correlazione tra i sistemi stomatognatico e oculomotore nel determinismo della postura. Elselvier 2009;34:235-42.

43.Meyer J, Baron JB. Variation de l'activité tonique posturale orthostatique au cours d'une anesthésie règionale du trijumeau. Agressologie 1973;14:37-43. 44.Guimarāes LHCT, Galdino DCA, Martins FLM, Vitorino DFM, Pereira KL, Carvalho EM. Comparação da propensão de quedas entre idosos que praticam atividade física e idosos sedentários. Rev Neurocienc 2004;12:68-72. 45.Ahmadi M, Liu JX, Bränström T, Andersen PM, Stal P, Domellof FP. Human Extraocular Muscles in ALS. IOVS 2010;51:3494-501.

46.Bicas HEA. Visão binocular: Estrabismos. Ribeirão Preto, Medicina 1997;30:27-35.

47.Mashima K, Bessineton JC, Baron B. Influence of permanent magnetic Field on tonic postural activity. Medica Physica 1986;9:37-40.

48.Beltrán I. Plantillas posturales experoceptivas. Revisgta Del instituto de posturologia y podoposturologia 2008;1:1-16.

49.Kandel ER. Fundamentos de neurociências e do comportamento. Rio de Janeiro: Guanabara Koogan; 1997, 600p.

50.Jacob filho W, Souza RR. Anatomia e Fisiologia do Envelhecimento. In: Papaléo Netto M, Carvalho filho ET. Geriatria: Fundamentos, Clínica e Terapêutica. São Paulo: Atheneu, 2004, p.31-40.

51.Carvalho filho ET. Fisiologia do Envelhecimento. In: Papaléo Netto M. Gerontologia: A velhice e o envelhecimento em Visão Globalizada. São Paulo: Atheneu, 2005, p.60-70.

52.Soares MA, Sacchelli T. Efeitos da cinesioterapia no equilíbrio de idosos. Rev Neurocienc 2008; 16: 97-100. 
53. Roll JP, Roll R. Kinesthetic and motor effects of extraocular muscle vibration in man. North-Holland. Eye movements 1987;57-67.

54.Kavounoudias A, Roll JP, Roll R, Gilhodes JC, Bouquerel A. Résponses posturales orientées induites par stimulations. J Physiology 2001;532:869-78. http://dx.doi.org/10.1111/j.1469-7793.2001.0869e.x
55.Cohen H. Neurociência para fisioterapeutas: incluindo correlaçóes clínicas. 2 ed. São Paulo: Manole, 2001, 494p.

56. Quercia P. La proprioception pour la prise em charge dês enfants dyslexiques. Soins pédiatrie-puéruculture 2008;243:28-32. 